\title{
BMJ Open How do males recover from eating disorders? An interview study
}

\author{
Gunn Pettersen, ${ }^{1}$ Karin Wallin, ${ }^{2}$ Tabita Björk ${ }^{3}$
}

To cite: Pettersen G, Wallin K, Björk T. How do males recover from eating disorders? An interview study. BMJ Open 2016;6: e010760. doi:10.1136/ bmjopen-2015-010760

- Prepublication history for this paper is available online. To view these files please visit the journal online (http://dx.doi.org/10.1136/ bmjopen-2015-010760).

Received 10 December 2015 Revised 12 July 2016 Accepted 19 July 2016

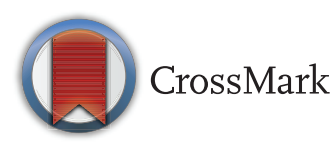

For numbered affiliations see end of article.

Correspondence to Gunn Pettersen; gunn. pettersen@uit.no
ABSTRACT
Objectives: The aim of the current study is to investigate what males experience as helpful in their recovery process from eating disorders (ED). Methods: Qualitative in-depth interviews within a phenomenological approach, and using content analysis to excavate overarching text themes.

Setting: Norway and Sweden.

Participants: Included were 15 males with an age range from 19 to 52 years. Duration of illness varied between 3 and 25 years of experience with anorexia nervosa $(n=10)$, bulimia nervosa $(n=4)$ or ED not otherwise specified $(n=1)$.

Results: The content analysis revealed four main categories, that is, 'the need for a change', 'a commitment to leave the eating disorder behind', 'interpersonal changes' and 'searching for a life without an eating disorder'. These categories comprise features like motivation to change, gaining structure in eating situations, a re-learning of personal and interpersonal skills as well as accepting losses and starting a reorientation of identity and meaning. We noted a rather goal-oriented approach to help seeking and a variation in how the males engaged their social network in resolving the challenges associated with the recovery process. Still, the overall nature of the recovery process highly accords with what has been reported for women.

Discussion: A clinical implication from our findings is that symptom relief is important to facilitate good circles of improvement, but that the nature of the recovery process would require a wider perspective in treatment. Clinicians may also be informed about challenges related to an instrumental approach to help seeking reported in this study.

\section{INTRODUCTION}

Eating disorders (ED) are uncommon disorders, but studies shows that ED affects both males and females in different ages. ${ }^{1-3}$ The historically skewed gender ratio is reflected in theories of aetiology, former diagnostic criteria and clinical research. However, those studies, which have included males, have found few gender differences in terms of aetiology, symptomatology, treatment response and outcome. ${ }^{4}$ In the literature on females with ED, some studies have focused on the outcome 'process', and the nature of

\section{Strengths and limitations of this study}

Strengths are its originality as being one of few studies of the recovery process among males with an eating disorder across age and treatments and where the sample size was sufficient to capture the richness and variations in the experiences of recovery.

- Limitations are that some standardised validation procedures were not supplementing the clinical judgement regarding diagnoses and recovery.

- Although all participants reported within every theme, we did not collect the exact number of participants.

recovery in particular. ${ }^{5}$ In the present paper, we aim to explore the nature of this process among males, where there is a gap of knowledge in the literature.

There are several possible reasons why the nature of males' recovery could differ from those of females. First, it could be that trigger factors and personal reasons for taking actions to recover may be different from those of females. A second possibility relates to feelings of shame of having a 'female' illness. This shame may delay seeking treatment, with the consequences of increasing the risk of a slower recovery process and thereby prolong the duration of illness and raising the probability of a poorer prognosis. ${ }^{2}$ Moreover, although a recent review of ED in males ${ }^{6}$ indicates substantial improvements in clinician's ability to detect and treat males with ED, treatment services may still be suboptimal in various treatment settings. If so, suboptimal clinical services may halt a recovery process given that the shame of having a 'female illness' may make a male with ED more vulnerable to experiences of being ignored or misunderstood by a therapist. ${ }^{7}$ In addition due to possible shame of having a 'female illness', males may be more concealed about their ED and thereby blocking for the contribution from their social network to their recovery process. 
Study of the recovery process can benefit from a qualitative approach, since it enables a deeper understanding from the patient's perspective. This perspective is often missing in traditional outcome studies. ${ }^{12} 8$

Much is known about the recovery process among women, and it starts with a wish to change, often facilitated by important persons in their lives. ${ }^{9-11}$ Other elements contain the development of the ability to identify and express feelings, in an empathic, non-judgmental understanding milieu ${ }^{5}$ as well as improving self-esteem, body experience and to learn more functional problem-solving skills. ${ }^{12}$ A review of female studies ${ }^{13}$ shows a number of 'recovery-promoting agents', notably interpersonal relations, treatment, self-help and positive life events that trigger self-determination and motivation to explore alternatives to an ED-identity. The recovery process appears as continuous rather than dichotomous in nature, where the individuals need time to come to terms with grief over lost time and finding other ways of living the life without an ED, and learn to practice more functional self-regulative behaviours. ${ }^{14}{ }^{15}$ Women also tend to experience the recovery as spiritual process or like a journey to self, with turning points and shifts in relationships that enabled different ways of belonging, self-acceptance and agency. ${ }^{16}$ An integrative model of the nature of female's recovery process ${ }^{8}{ }^{13}$ outlines weight normalisation and reduction of symptom frequency and severity as the 'necessary' prerequisites for progress of the 'sufficient' domains, that is, the resolving of psychological issues, existential issues, as well as interpersonal and social aspects. ${ }^{8}$

Although small-scaled a few studies provide some knowledge about males' experiences relevant to recovery. Most of them have focused on inverse factors, like barriers for help-seeking and delay in seeking treatment due to shame or an inability to recognise symptoms and behaviour as signs of an ED and a lack of appreciation of male issues in the treatment process. ${ }^{17}{ }^{18}$ Positive treatment factors relevant to recovery appear to be the importance of feeling understood, listened to and cared for in treatment or in support groups ${ }^{19}$ as well as hospitalisation in order to get away from home, family and work. ${ }^{20}$ General factors positively associated with a recovery process have been found to be to eat regularly and healthy, to avoid alcohol and paying attention to both the content of the food and what time it was eaten. However, a heavy focus on treatment-related issues leaves much to be explored about possible treatment-unrelated factors contributing to recovery. A more complete account of the recovery process may be relevant to put treatment into a context, which in sum contributes to ease the recovery process and thereby shorten the duration of the illness and raise the probability of a favourable course. This study is the third one in our research project, where one previous study focused on the males' experiences of life after recovery. Questions in the first study concerned whether they perceived themselves as recovered, and in what areas it was evident and in what way. ${ }^{21}$ The second study focused on the attributed causes of their ED, and the participants were asked to identify their perceived causes of their ED and to share how their social, family and personal situation functioned at time for onset. ${ }^{22}$ The aim of the current study is to investigate what males experience as helpful in their recovery process from ED.

\section{METHOD}

\section{Patients and procedure}

Eligible participants were former male patients who had completed their treatment for a Diagnostic and Statistical Manual Fourth Edition (DSM-IV) ED, and who had experienced recovery. We approached specialised ED-units in Norway or Sweden to help identify such patients and deliver study information. We did not ask the ED-units for formal documentation according to the routines for diagnosing and there was no formal diagnostic interview for the purpose of the current study.

After approval from the Regional Ethical Committees of Medical and Healthcare Research in Northern Norway and Sweden, respectively, 17 men were provided proper study information by their former therapists. Of these, 15 gave their written consent to be qualitatively interviewed by the authors for about 1-2 hours about their experiences of recovery. We interviewed every participants once, and with three separate lines of questioning according to the focus of current study, as well as the two previous studies from this project. ${ }^{21} 22$ Some overlap between the three parts were though present due to the dynamics of the conversation but this was handled in the analysis by keeping a sharp focus on the aim and research question for each study and by discussions in the research team.

Every interview was recorded and transcribed consecutively, and was guided by the following gender-neutral question "what was helpful for you in your recovery process?" Geographical distances made it convenient to perform interviews at the participants' hometown or other locations chosen by participants and researcher of practical reasons. The interviews were conducted from October 2010 to July 2011. Judging from statements about current job status, income and present or previous occupation or profession appearing during the interviews the participants included appeared to come from all socioeconomics strata. Moreover, the males had received a wide range of treatments during their stay at the specialised ED-clinics, like medications, individual treatments, group or family treatments, dietary advice and physiotherapy, often given simultaneously and in a mixture of inpatient or outpatient status. The participants' age ranged from 19 to 52 years (mean=23 years). The original diagnostisation made by the specialised ED-units yielded 10 participants with anorexia nervosa $(\mathrm{AN})$, four with bulimia nervosa $(\mathrm{BN})$ and one with an unspecified ED (NOS). The age range for onset for the 
ED was from 10 to 21 years and the range for duration of ED reported was 3-25 years. Hence, all had a long history of considerable symptom load, sometimes diffusing across the ED diagnoses. In addition, those males low in weight had been hospitalised for medical complications. We did not ask specifically about comorbid mental conditions, but during the interviews participants themselves reported commonly compulsive physical exercise, high self-demands, low self-esteem, depressive episodes, as well as inner beliefs of not being good enough and likable to others. In addition, they reported body dissatisfaction and feelings of not being thin or muscular enough, a long duration of symptoms, a delay in treatment seeking as well as a massive hiding of symptoms from family members and other close relations for years. Vocational problems elicited by the ED-symptoms were also present.

\section{Data analysis}

Content analysis is suited to elicit meaning, interpretations, consequences and context and the analysis in this study was guided by the five steps outlined by Graneheim and Lundman. ${ }^{23}$ In the first step, all authors compared the transcripts with the audiotaped interviews to check the accuracy of the texts, and then they independently read the interview texts several times to get an overall impression of the material. In the next step, the first author (GP) marked all statements containing the word 'recovery,' or other words related to the study aim. The third step included rereading the transcripts adding further notes and aspects related to 'recovery' as a theme as well as identifying codes, that is, units of meaning reflecting the texts. The third step also included a further reading of the texts in order to filter out irrelevant information, reduce the main meaningcarrying units and to identify pattern and nuances. The meaning units were defined, condensed and reformulated, continuously checking the text for relevancy and accuracy. The fourth step was coding the meaning units, to identify the categories. Hence, the categories were derived from the transcribed texts, and not from the pre-set guideline questions for the interviews. The purpose of the final validation step was to secure the credibility of the results. Here the other authors (KW, TB) scrutinised the participants' statements in relation to the categories. The three authors then discussed the results of the analysis until agreement was reached. In this study, consensus was reached with respect to four categories, that is, 'the need for a change', 'commitment to leave the ED behind', 'interpersonal changes' and 'searching for a life without the ED'. All participants reported issues relevant for all categories, but for obvious reasons these were not represented in all the quotes, that is, the condensed units of meaning. All quotes from participants are presented with pseudonyms, age at the time of the interview and with their former ED-diagnosis.
RESULTS

\section{Category 1 -the need for change}

This category concerns issues from the period when they understood that something was wrong, that their relation to food, weight, body and exercising dominated in a negative way, and where they experienced the need for a change. This need is subcategorised into 'admitting the problem', 'treatment needs in the early phase' and 'stabilising nutrition and weight', respectively.

\section{Admitting the problem}

The process of understanding and admitting that they had an ED had taken a long time, and some reported many years with struggling without speaking with others about their problems. To admit having an ED included admitting that food, weight and body appearance controlled or dominated all domains of life, like for instance their relations to family members, friends or others. Thus, they experienced daily life as rather chaotic and with feelings of being worried and 'fed up'. Some reported even having to quit job or education either temporarily or permanently because of living with the ED. Some of the males had been exercising like elite athletes do, and with a high drive to 'perfect' training. In sum then, the males retrospectively recalled the periods of their life with the ED before seeking treatment as chaotic or 'meaningless'. As a result, some of the males reported having nearly given up and described it like being in a crisis, for some exacerbating into suicidal ideations. Not everyone had a full understanding that their problem was an ED, but they came to a point where they understood that they needed help in order to move further.

Patric, 24 years, (AN), stated:

I came to a point I realised the need for help. I couldn't manage to eat and my only thought was- I can't live like this anymore, it's no life.

Gary 21 years, (AN) described it like this:

It was a general breakdown; I was so down on my knees that nothing mattered any longer. I felt that everything was meaningless and worthless. When I went to see the doctor, I just told him all, I had nothing to lose.

Realising the negative consequences and admitting having a problem was thus important the first period of the recovery process.

\section{Treatment needs in the early phase}

Realising the need for help, some of the males contacted health professionals themselves. However, most of them reported having been pushed into it, or even forced by a close family member or a friend, however, not due to their social or family role as a male. In retrospect, many realised that by so doing their parents or close friends almost saved their life. Indeed, they were 
grateful, at least in retrospect that someone else took over the control and of feeding and eating.

Jacob, 19 years, (AN) said it in this way:

My parents took the initiative to seek for help. I was admitted to the hospital and I thought I should be discharged the same day, but they took an EKG and I was obviously very sick and needed tube feeding. I was kind of shocked, I didn't realise that I was in a so bad condition.

A citation from Oscar, 21 years, (AN):

It was a relief that others just could take the control over the food and decide what I should eat and the hospital stay could provide structure and frames to regulate my eating.

Some of the males started their recovery process with hospitalisation due to severe weight loss and food avoidance. Others contacted a general practitioner or started with outpatient treatment. No matter what kind of treatment they sought, the need was somewhat the same; they needed help because they had realised that they could not manage the situation on their own.

\section{Stabilising nutrition and weight}

The males highlighted the importance of stabilising eating, nutrition and weight in the early phase of the recovery, and many recalled the structure of hospital treatment as helpful, notably as facilitating work on more difficult issues like overeating and purging, which some had strived with for years.

As Christopher, 21 years, (AN) expressed:

I needed a break from everything- I wanted to be hospitalised and I hoped that they could close the doors so I didn't get the opportunity to overeat and throw up.

Owen, 31 years, $(\mathrm{BN})$ said it in this way;

I joined a "luncheon group" at the hospital and that changed my attitude markedly. I got another and better structure around food and managed to keep the meals to fixed time during the day.

Others also reported the benefit of having had to relearn 'how to eat'. It was a process learning to eat in a new way, and it took time, as Paul, 48 years, (BN) said:

It took at least one year before I learnt to eat. I went to a dietician who taught me how to organise my eating into breakfast, lunch and dinner. Even if ED are not just a matter of food, it is also about food and I was totally "out of place" on this food thing.

As the last citation illustrates, gaining structure was a time consuming struggle.

\section{Category 2-commitment to leave the ED behind}

After the initial stabilising of food intake and weight, the main issue was how to leave the ED behind. This category consists of the subcategories 'searching for a balance', 'expectations towards treatment'.

\section{Searching for a balance}

The males reported being challenged to let the ED behind and replace it with new coping strategies. Despite the fact that the males had experiences all the negative consequences related to the $\mathrm{ED}$, they also reported that the ED had been their functional coping strategy for years. Some even described their ED as having been their best friend. Hence, a challenge was to handle the ambivalence of change, that is, looking for ways towards a less chaotic life, but also letting go of some 'advantages' that the ED represented.

The males reported challenges in finding a balance between rest, sleep and activity. Moreover, from previously being compulsive about physical exercise, the recovery process meant learning to convert exercise into a positive contribution in terms of balance and a contact with own needs. As Mike, 36 years, (AN) expressed it:

I exercised several times a day and it was very compulsive. On the other hand, the exercise has been very important for my recovery and I will never live a life without exercise. Now, however, I have learnt to ask myself-why do I have to exercise now? In addition, I learnt to sit down and think that I need both rest and activity. I also had to be more flexible about when to exercise.

The citation illustrates the need to examine the motives for exercising, and search for the joy of exercising, instead of pursuing the aim of burning calories. Almost the same process was relevant with respect to the rules related to meals.

As Jacob, 19 years, (AN) said about how he found balance between resting and exercising:

'I exercise quite a lot together with my friends, well, occasionally I also run by myself and if I think to myself that I would like to run 4 to 6 times per week then $I$ know it is a bit too much. You need maybe one or two days to recover after exercise. The day after exercise I rest and take it easy and do something completely different.

Gradually, the males managed to loosen up their detailed mealtime schedules, but also to gain more flexibility by challenging personal rules about what one 'can' do and 'not do'. The males described how the focus on regulation of food and activity as well as self-care made them gradually stronger and improved in many areas of their life.

Promoted by therapy the males started a process with increasing self-care and more regular patterns of living. Also, they gradually learnt to think better about themselves, be more kind to oneself, to discover own needs and be able to fulfil them, and thus, to 'deserve' entering a recovery process. Another issue was to understand which kind of purposes or functions ED-symptoms served in their life and, in essence, why they developed 
an $\mathrm{ED}$ in the first place. As consequence, the males came to understand that the ED-symptoms served as a twisted way to express themselves emotionally.

Later in the recovery process many of the males restarted with activities they liked before step-by step, with the result that there was less time to think of food and a positive circle emerged. Others began with new activities, of which the ED earlier had been a barrier. For some it was important to keep up leisure activities like sports, travelling or playing music, while others managed to take up again their activities after a more intensified treatment. Overall, leisure activities became 'a free space', where it was easier to manage the ED-symptoms.

More time to do things was frequently mentioned along with other positive circles because of symptoms being more stable. Being able to have a daily occupation, being able to have a job, go to school or having a daily occupation were highlighted by some participants as important in the recovery process. Some though, asked for a sick leave in order to concentrate more fully on their treatment and recovery process.

\section{Expectations of treatment}

In general, the males had high expectation towards treatment. It was important for them to find a therapist who they could trust and talk to about their ED-related problems. Some expressed that when they finally decided to put so much effort into treatment they would not waste their time on inefficient services. Some were thus quite goal-orientated and instrumental and did not hesitate to quit treatment if they after some time did not get along with their therapist. Some were eager to come to grip with the 'whys', but the main development was just to learn how to find a way 'out' of the illness. The demands were also evident in terms of the personal effort, investment and engagement they put in therapy in order to get the most out of it.

The therapist was the person they spoke most openly with and sometimes the only person they talked to about the ED. All participants reported high personal investment and engagement in their therapy. This is shown in the huge effort they were willing to make to get most out of their treatment illustrated as follows:

I drove my car 150 kilometres each way to the therapist, so I was rather motivated at that time and I used my selfdetermination. When I decide to do something, I really make an effort, and when I decided to give treatment a try, the driving distance was not a problem at all." Darry, 34 years, (AN)

Thus, the males gave themselves some credit for their recovery, but all of them said that they would not have made it without professional help, as Robert, 45 years, (BN) said:

It has been a struggle, but I have had the fortune of receiving good treatment. I could not have managed it on my own, but at the same time I have my resources inside me that made me go through with recovery and start a life without the ED. I have gradually learnt to use my strength and my resources in a right way.

\section{Category 3-interpersonal changes}

This category includes interpersonal changes, notably acquiring more flexibility in the social relations and learning to express better own needs. The subcategories were 'expressing own needs' and 'relating to others in new ways'.

\section{Expressing own needs}

The males reported how they gradually learnt to become more aware of own needs and to express them to others. The males changed their history from being pleasers, who always said 'yes' if someone asked for something and seldom asserted their own needs and boundaries to becoming 'boundary setters'. As stated by Philip, 31 years (AN):

Before it was very important for me that my friends thought I was ok, but now it is more important for me that I think it is ok to be with my friends. If I think it is ok, I am sure they do as well. I have started to ask myself —what are my needs?

And Oscar, 21 years (AN) said it like this:

I have become more independent as a person, I do not longer need to agree with others. I can tolerate disagreement and even speak my mind against other opinions.

\section{Relating to others in new ways}

The recovery process also included a change in their understanding of relations. Facilitated by treatment, they understood more about ED and the mechanisms of symptoms, and this made it easier to find the right words to explain their ED-symptoms to family members and close friends. Some reported an indirect benefit from interpersonal relations in the sense that job, colleagues and friends made a supportive impact by providing social control and an external structure in order to control the frequency of symptoms.

Some also understood that in order to start to recover and to secure continuing the recovery process, they had to distance themselves from difficult relationships, like a violent father or a mentally sick mother, realising that no support could ever be provided. When being more social, they became more self-confident and therefore, they stood up for their own needs when relating to others. As stated by Alexander, 22 years (AN).

I have learnt a lot about myself during this process and now I know more what kind of life I want to live. It is important with social network and to see the value of friends and having someone to really care about. It is also like-you have to accept yourself before you are able to love others. It is hard to have close relationships when you have so much trouble yourself. After a while, I was 
able to be social with others, and I managed to keep a conversation going without thinking of other things, I could really listen to others and I became more participating and present in the moment.

Mike, 36 years (AN) explained it this way:

I have become more free and I am not longer so hard on myself- I have gone from being "looked" into myself to become "unlocked". For example, now I am able to enjoy and handle being touched by my girlfriend, I can cry together with her and I can feel everything more strongly than before. To feel more is a big thing for me."

\section{Category 4-searching for a life without the ED}

The males had spent years of their lives living with an ED, thus missing other experiences and opportunities. The recovery process included feelings of grief over such losses, but also the need for reconciliation and a search for normality and an identity without an ED were experienced as important. This category consists of the subcategories 'accepting the losses' and 'finding oneself'.

\section{Accepting the losses}

Nearly all the males struggled with a grief related to having been preoccupied with the ED and the related problems for so many years. They had experienced that the years with an ED had caused losses, for instance a dropout of school, a sick leave from work or having sparse or no experiences with being in close relationships. David, 52 years (BN) said:

'I can feel a grief because I have spent 25 years of my life on the bulimia, and now I feel that many trains have passed by'.

Even if the males in general could feel a grief over the losses, at the same time they had some expressions that described how this process had made them stronger and more and more aware of their own needs.

'When I had my bulimia, I didn't have a need for or place in my life to have a close relation, but during the recovery process the need for a family and own children came up' (Robert, 45 years, $(\mathrm{BN})$.

This citation also illustrates progress and recovery in the sense that new needs elicited grief for something (ie, bulimia) which previously had been experienced as 'functional'. Moreover, to understand development of the ED was described as helpful to realise the psychological pain in order to be able to look ahead. After years of struggling with the ED many of the males also expressed that they had become more empathic, understanding and compassionate with others who were experiencing problems in their lives.

\section{Finding oneself}

Owing to years of suffering from ED a common description was that the disorder had become a part of their identity. They reported that during the recovery process they were uncertain about what is defined as normal and what actually a recovery from an ED is all about. Hence, during the recovery process the males had asked themselves "who am I without the ED?", and "how will my life be without an ED?" These rather existential questions were in essence, partitioned out into many daily life contexts. Apart from their relearning of basic regulative issues with respect to food, sleep, activity, emotions and reactions, they were furthermore occupied with a relearning of ordinary behaviours and emotional reactions and daily rules of ordinary social interaction with others. The males reported difficulties with eg, to know whether a strong emotional reaction was 'normal' or due to their ED-history. As Jonathan, 21 years (ED-NOS) asked: "How sad is it normal to be after a split-up with a partner?"

This citation illustrates that the males felt it difficult to sort out whether their reactions or feelings were coloured by their former identity as an "ED-sufferer" (and hence possibly not 'normal') or whether they mirrored their 'true selves'. Several of the males also remarked that they characterised themselves as vulnerable. As Robert 45 years $(\mathrm{BN})$ said:

I know that I am an emotional and sensitive human being, and not very robust and not someone who takes easy on stresses and strains. When for instance my parents will die I think this will be very hard for me. However, it is reassuring that I can contact my general practitioner or other kind of help if needed.

During the recovery process, the males were actively taking part in social life, but there were variations on how open they were about their ED. Some had a fear of as well as experience with being stigmatised and that others should attribute all kinds of behaviours to their ED-history. To avoid stigmatisation and additional problems in the orientation of identity, some of them had made a choice to be selective with respect to whom they shared this ED-history. However, there were also males who had good experiences with openness in the recovery process and males who described openness as a relief that was helpful for the reorientation process.

\section{DISCUSSION}

This study focused on how the males described their recovery process from ED. We found four descriptive categories, that is, 'the need for a change', 'a commitment to put the ED behind', 'interpersonal changes' and 'searching for a life without an ED'. These categories as a whole depict a timeline and the total recovery process ending with a reorientation of life where the ED was history. Moreover, and hardly surprising, admitting to having an ED was the first theme the males mentioned as initiating their recovery. This is almost a prerequisite for even starting a recovery process.

Prior to, and in the other end of the recovery process males reported a chaotic period where ED symptoms 
dominated all domains of life. All of the males realised that they had problems for which they needed professional help, but there were variations in realising that the problems indicated ED in particular. Moreover, prior to some kind of 'decision' or the experience of a 'turning point', these males had considerable doubts and ambivalence. These findings concur with those reported for women ${ }^{24-26}$ thus indicating truly gender neutral change processes.

While the males achieved a more structured eating behaviour, they gradually also learnt to better recognise and understand their own personal needs. In return, this led to the ability to being more self-caring and compassionate. Our findings indicate that increased self-care as well as self-regulation are important aspects of the recovery process in the sense that they set in motion positive circles with opening up the often strict cognitive schemas and rules, a better structure and relation to food, resulting in less shame, more self-acceptance and eventually, in a better social functioning. Moreover, our findings indicate that regulative issues should not be restricted to affective control, but may comprise the full spectrum of life domains, similar to what has been reported ${ }^{14}$ among females in recovery from an ED.

The interviews also revealed the importance of healthcare professionals for a good recovery process, notably in terms of helping the males to sustain self-regulation and self-care activities. Moreover, it is noteworthy that professional helpers were for some of the males almost the only persons they talked to about the ED and the associated problems. Even so, they were not afraid of setting demands and they would not 'waste' their time with treatment, which they believed were not beneficial to them. In some ways then, these males took a rather instrumental approach in one's own recovery process (once they had made a decision to recover), and in this process they made use of a sometimes strong and positive willpower. Nevertheless, this goal-orientation did not seem to shorten the often long and demanding journey towards recovery. The males were driven by compliance, following the instructions from therapists in order to recover. The instrumental approach to treatment stands out as a possible gender-specific finding in need of future explorations.

Our findings indicate that the recovery process consists of several elements. One element is the control of ED-symptoms and their complicating elements. Hence, the males reported that the process of recovery is a matter of lowering the symptom load, to loosen strict rules for food intake, to let go of self-stigmatisations, to experience less somatic complications and to experience ED-symptoms that do not dominate daily life.

Another element of the recovery process comprises psychological and social issues. The males reported how the ED prevented them from taking part in social activities. However, during the recovery process they began to strive for social support and more openness about their problems. The social network consisted of many sources, that is, people who stand for continuity, who had been there all the time and knew the person before the development of the ED. An important aspect of recovery was depicted in the participant's wish to make better use of the social network as a platform for hope and a wish to function well in social settings. This theme concerned developing the intrinsic need to take part in, and enjoying social activities and not just to please other people.

Our results show that the later stages of males' recovery process consisted of existential elements, like questioning their opinions about the meaning of life without the ED. This part of the recovery process indicates a cognitive and attentional shift from being preoccupied with the beliefs of controlling food intake by dieting, vomiting or excessive exercise. Obviously, this shift released an important 'psychological free space', and a rethinking of one's identity and goals of life.

Taken together, our findings concur with themes and change processes, which have been identified among women in recovery from an ED. ${ }^{8}{ }^{13-15}$ This may indicate a universal nature of change and recovery from ED. On the other hand, and possibly equally gender related, is the fact that the males had concealed their ED for a long time and delayed to seek treatment. This is indicated by the high frequency of hospitalisation as the first line of treatment due to symptom severity.

This study's strengths are its originality as being one of few studies on the recovery process among males with an ED across age and treatments where the sample size was sufficient to capture the richness and variations in the experiences of recovery. On the other hand, three limitations should be mentioned. First, although all participants reported within each of the four themes, we did not collect the exact number of participants within each theme. Second, no semistructured diagnostic procedure was carried out either when entering treatment nor at recruitment to this study to validate experienced clinicians' judgement. In addition, no standardised measures were used to capture current level of ED-symptoms, but it may be argued that this limitation is of less importance because we were interested in the experiential perspective, and that at present, no standardised instrument is available which has sufficient content validity to capture the multiple concept 'recovery'. Finally, our findings are relevant for Caucasian males, and how former male patients from non-western cultures experience their recovery process remains to be investigated in future studies. Also a matter for future studies is to investigate whether the present findings also apply to males recruited from general clinics, or from the general population.

\section{CONCLUSION}

A clinical implication from our findings is that symptom relief is important to facilitate good circles of improvement. Moreover, and similar to findings on females' recovery process, our study points to the need to address a wider perspective, that is, to support patients' recovery through social reorientations, personal reconciliations and coming to terms with existential issues. Male specific 
recommendations to therapists are to acknowledge that ED-symptoms do occur among males, and to design a straightforward treatment plan to deal with current symptoms and future challenges.

\section{Author affiliations}

${ }^{1}$ Department of Health and Care Science, University of Tromsø-The Artic University of Norway, Tromsø, Norway

${ }^{2}$ Department of Clinical Science Lund, Child and Adolescent Psychiatry, Lund University, Lund, Sweden

${ }^{3}$ Faculty of Medicine and Health, University Health Care Research Center, Örebro University, Örebro, Sweden

Contributors GP, KW and TB were all responsible for the planning of the study, the data collection and the analysis. All authors contributed to the manuscript.

Funding This research received no specific grant from any funding agency in the public, commercial or not-for-profit sectors.

Competing interests None declared.

Patient consent Obtained.

Ethics approval Regional Ethical Committee of medical and healthcare research and the regional Ethics Review Board in Uppsala Sweden (D. number 2009/118) and the Regional Ethical Committee for Medical and Healthcare Research in Northern Norway.

Provenance and peer review Not commissioned; externally peer reviewed.

Data sharing statement No additional data are available.

Open Access This is an Open Access article distributed in accordance with the Creative Commons Attribution Non Commercial (CC BY-NC 4.0) license, which permits others to distribute, remix, adapt, build upon this work noncommercially, and license their derivative works on different terms, provided the original work is properly cited and the use is non-commercial.

See: http://creativecommons.org/licenses/by-nc/4.0/

\section{REFERENCES}

1. Rosenvinge $\mathrm{JH}$, Pettersen G. Epidemiology of eating disorders, part I: introduction to the series and a historical panorama. Adv Eat Disord: Theory, Res Pract 2014;3:76-90.

2. Rosenvinge $\mathrm{JH}$, Pettersen $\mathrm{G}$. Epidemiology of eating disorders part II: an update with a special reference to the DSM-5. Adv Eat Disord: Theory, Res Pract 2015;3:198-220.

3. Smink FRE, van Hoeken D, Hoek HW. Epidemiology of eating disorders: incidence, prevalence and mortality rates. Curr Psychiatry Rep 2012;14:406-14.

4. Gueguen J, Godart N, Chambry J, et al. Severe anorexia nervosa in men: comparison with severe AN in women and analyses of mortality. Int J Eat Disord 2012;45:537-45.

5. Beresin EV, Gordon C, Herzog DB. The process of recovering from anorexia nervosa. J Am Acad Psychoanal 1989;17:103-30.
6. Raevuori A, Keski-Rahkonen A, Hoek HW. A review of eating disorders in males. Curr Opinion Psychiatry 2014;27:426-30.

7. Griffiths S, Mond J, Li Z, et al. Self-stigma of seeking treatment and being male predict an increased likelihood of having an undiagnosed eating disorder. Int J Eat Disord 2015;48:775-8.

8. Pettersen G. Eating disorders: studies of understanding and recovery. Trondheim, Norway: Norwegian University of Sciences and Technology, 2007.

9. Nilsson K, Hägglöf B. Patient perspectives of recovery in adolescent onset anorexia nervosa. Eat Disord 2006;14:305-11.

10. Tozzi F, Sullivan P, Fear J, et al. Causes and recovery in anorexia nervosa: the patient's perspective. Int J Eating Disord 2003;33:143-54.

11. Pettersen $\mathrm{G}$, Rosenvinge $\mathrm{JH}$. Improvement and recovery from eating disorders: a patient perspective. Eat Disord 2002;10: $61-71$

12. Vanderlinden $\mathrm{J}$, Buis $\mathrm{H}$, Pieters $\mathrm{G}$, et al. Which elements in the treatment of eating disorders are necessary "ingredients" in the recovery process? A comparison between the patients' and therapists' view. Eur Eat Disord Rev 2007:15:357-65.

13. Rosenvinge $\mathrm{JH}$, Pettersen $\mathrm{G}$. Towards a comprehensive model of recovery. In: Jáuregui Lobera I, ed. Relevant topics on eating disorders. Madrid: InTec Publishing House, 2010:269-92.

14. Pettersen G, Rosenvinge JH, Wynn R. Eating disorders and psychoeducation-patients' experiences of healing processes. Scand J Caring Sci 2011;25:12-18.

15. Pettersen G, Thune-Larsen KB, Wynn R, et al. Eating disorders: challenges in the later phases of the recovery process: a qualitative study of patients' experiences. Scand J Caring Sci 2013;27: 92-8.

16. Moulding NT. Gendered intersubjectivities in narratives of recovery from an eating disorder. Affilia: J Women Soc Work 2015; doi:10.1177/0886109915576519

17. Räisänen $U$, Hunt $K$. The role of gendered constructions of eating disorders in delayed help-seeking in men: a qualitative interview study. BMJ Open 2014;4:e004342.

18. Thapaliyal T, Hay P. Treatment experiences of males with an eating disorder: a systematic review of qualitative studies. Trans/ Dev Psychiatry 2014;2:25552.

19. Robinson KJ, Mountford VA, Sperlinger DJ. Being men with eating disorders: perspectives of male eating disorder service-users. $J$ Health Psychol 2013:18:176-86.

20. Dearden A, Mulgrew KE. Service provision for men with eating issues in Australia: an analysis of organisations, practitioners, and men's experiences. Austr Social Work 2013;66:590-606.

21. Björk T, Wallin K, Pettersen G. Male experiences of life after recovery from an eating disorder. Eat Disord 2012;20: $460-8$

22. Wallin K, Pettersen G, Björk T, et al. A qualitative study of males' perceptions about causes of eating disorder. Psychology 2014:5:1813-20.

23. Graneheim U, Lundman B. Qualitative content analysis in nursing research: concepts, procedures and measures to achieve trustworthiness. Nurse Edu Today 2004;24:105-12.

24. Hsu LKG, Crisp A, Callender J. Recovery in anorexia nervosa- the patient's perspective. Int J Eat Disord 1992;11:341-50.

25. Serpell L, Treasure J. Bulimia nervosa: friend or foe? The pros and cons of bulimia nervosa. Int J Eat Disord 2002;32:164-70.

26. Serpell L, Treasure J, Teasdale J, et al. Anorexia nervosa: friend or foe? Int J Eat Disord 1999;25:177-86. 